\title{
CONSIDERAÇÕES SÔBRE A LEI DE DALTON REFERENTE ÀS MISTURAS GASOSAS
}

Armando Foá

Fm trabalho anterior (18), admitimos que todos os gases de uma mistura em movimento numa canalização, em determinado ponto, se acham sujeitos a uma mesma pressão $p$. Tal hipótese precisa talvez de justificativa, pois contradiz à lei de Dalton, segundo a qual, numa mistura, cada gás se acha sujeito a uma pressão parcial igual à que teria se, com a mesma temperatura, ocupasse sòzinho o volume total do recipiente que a contém.

Existe realmente a contradição, mas parece-nos que provém do fato de a lei de Dalton fornecer uma explicação inexata a fenômeno físico real.

$\mathrm{Na}$ verdade, a teoria cinética dos gases nos diz que, numa mistura, as moléculas perdem a sua individualidade e uniformizam as suas energias cinéticas de translação, assim como as de rotação: conseqùentemente, em pouco tempo, se obtém, em todo o recipiente, uma distribuição pràticamente uniforme das moléculas dos vários gases no espaço. Nestas condições, a pressão da mistura é o resultado dos choques entre as moléculas ou entre estas e as paredes do recipiente. $A$ nosso ver, a pressão deve ser necessàriamente a mesma para todos os gases, manifestando-se como pressão total da mistura e assim, por exemplo, é evidenciada por um manômetro.

Ao contrário, a lei de Dalton faz supor que as moléculas de cada um dos gases conservam sua individualidade; ou melhor, deveriam elas possuir a capacidade de, por assim dizer, somente reconhecer a presença de moléculas homólogas, ao passo que não seriam capazes de perceber a presença de moléculas de natureza diversa.

Mas, a referida lei aplicada a uma mistura gasosa: $\mathrm{pV}=\mathrm{nRT}$, pode dar ensejo a duas interpretações (15) ; recordamos que $p, T$ e V são, respectivamente, a pressão, a temperatura e o volume total da mistura ; $R$, a constante dos gases perfeitos ; $n$, o número total de moléculasgramas presentes $e$, por sua vez, igual a $\left(n_{1}+n_{2} \ldots\right)$, correspondendo os números parciais às moléculas-gramas de cada um dos gases componentes da mistura.

Assim sendo, a fórmula pode ser escrita da seguinte maneira: $\mathrm{pV}=\left(\mathrm{n}_{1}+\mathrm{n}_{2}+\ldots\right) \mathrm{RT}=\mathrm{n}_{1} \mathrm{RT}+\mathrm{n}_{2} \mathrm{RT}+\ldots=\mathrm{p}_{1} \mathrm{~V}_{1}+\mathrm{p}_{2} \mathrm{~V}_{2}+\ldots$ 
Conforme se considere no segundo membro $\mathrm{V}_{1}=\mathrm{V}_{2}=\ldots=\mathrm{V}$, ou $\mathrm{p}_{1}=\mathrm{p}_{2}=\ldots=\mathrm{p}$, tem-se :

ou então:

$$
\mathrm{p}_{1}+\mathrm{p}_{2}+\ldots=\mathrm{p}
$$

$$
\mathrm{V}_{1}+\mathrm{V}_{2}+\ldots=\mathrm{V}
$$

\section{A primeira forma corresponde à interpretação de Dalton.}

Repetimos: tal interpretação não nos satisfaz, pois achamos que contradiz aos resultados da teoria cinética. Além disso, temos de admitir que cada gás ocupa todo o volume da mistura, o que, também, é um tanto difícil de se conceber. De-fato, embora reconheçamos que a matéria é pràticamente vazia, parece-nos que, no cômputo do espaço correspondente a uma determinada molécula, devemos considerar não só o espaço efetivamente ocupado pela substância material, mas também tôda a esfera de ação da molécula em questão, onde outra molécula não pode entrar. Supomos que cada molécula ocupa uma posição fixa, o que pode ser aceito, do ponto de vista estatístico. Assim sendo, a presença dum gás num determinado ambiente realmente limita o espaço disponível para outro, e não parece lícito admitir que cada gás ocupa todo êle. Com isso queremos dizer que não nos parece plausível a opinião de Gibbs ( *), segundo a qual um gás constitue um vazio para outro gás.

Resta a segunda interpretação (Leduc e Amagat), segundo a qual a pressão é a mesma para todos os gases, e o volume ocupado, proporcional ao número de moléculas-gramas de cada gás; isto é, cada molécula-grama ocupará igual volume, e como cada molécula-grama contém o mesmo número de moléculas, seja qual fôr a natureza do gás, cada molécula ocupará o mesmo volume, conforme exprime a lei de Avogadro.

A interpretação acima formulada não é aceita por G. Bruhat. Defato, diz Bruhat, deveríamos supcr, por exemplo, que, numa mistura a $0^{\circ} \mathrm{C}$, sob a pressão atmosférica, de ar e vapor de água, êste último esteja sob tal pressão, mas isto seria inadmissível.

Ao contrário, não nos parece que isto seja inadmissível; para prová-lo, comecemos por examinar como nasceu a hipótese das pressões parciais.

Considerando um vapor isclado, por exemplo vapor de água, a experiência demonstra que, para cada valor de temperatura, existe uma pressão limite, além da qual não é possível obter-se vapor, naquela temperatura $\left({ }^{* \star}\right)$.

Repetindo-se depois a mesma experiência, mas em presença de uma atmosfera gasosa, constata-se ser agora possível obter-se vapor, com a mesma temperatura, a uma pressão superior.

Não se podendo lògicamente admitir que o vapor tenha comportamento diferente nos dois casos, introduz-se então a hipótese de que,

(") Citado por J. Becquerel (4).

("*) Com maior exatidãc, a evaforação é em escala tão reduzida, que passa prd̀tica. mente despercebida. 
no segundo caso, o vapor esteja sujeito não à pressão total da mistura, mas só a uma parte dela (a assim chamada tensão parcial).

Todavia, parece-nos não haver necessidade de se recorrer a uma tal hipótese, aliás bastante estranha.

De-fato, a constatada lei da interdependência entre a temperatura do vapor e a pressão máxima na qual êle pode existir, pode também ser interpretada de modo diferente: precisamente, como lei de interdependência entre a temperatura e a máxima concentração possível de moléculas do vapor no espaço disponível (veremos daquí a pouco que, a nosso ver, é justamente esta a interpretação mais razoável) ; assim, na segunda experiência, o que de-fato limita a ulterior vaporização não é a tensão parcial do vapor, e sim a sua concentração molecular, a mesma variável que intervém no primeiro caso.

Passemos agora a examinar um pouco mais detalhadamente no que consiste o fenômeno da evaporação. Consideremos um líquido cujo estrato superficial superior está sujeito a duas ações opostas: de um lado, êle será empurrado pela massa líquida restante, que tende a produzir a evaporação; de outro, será empurrado pela atmosfera gasosa superior, que tende a favorecer a condensação. Conforme a preponderância de uma ou de outra das duas ações, teremos assim, como fenômeno macroscópico, evaporação ou condensação.

Aquecendo o líquido, a energia de tôdas as suas moléculas aumenta $\left(^{*}\right)$ e, conseqùentemente, a tendência para a evaporação. Assim se constata que esta tendência é tanto mais acentuada quanto maior a temperatura do fluido e quanto menor a pressão da atmosfera gasosa, que supomos, por simplicidade, invariável. $\bigcirc$ fato de, para um determinado valor desta pressão, se constatar evaporação completa do líquido sòmente quando fôr atingido determinado valor da temperatura, faz supor correspondência unívoca entre a temperatura e a tensão parcial, ou, por exemplo, a impossibilidade de existência do vapor de água, a $\mathrm{O}^{\circ} \mathrm{C}$, sob a pressão atmosférica.

Ao contrário, a nosso ver, não existe nenhuma tensão parcial, e o vapor de água pode muito bem existir naquelas condições ; o fenômeno, pensamos, se manifesta de acôrdo com as modalidades que passamos a expor.

De início, temos de reconhecer que, embora pequena, sempre há uma certa evaporação. De-fato, sendo a evaporação um fenômeno dinâmico, haverá sempre alguma molécula que consegue escapar da massa líquida restante. $O$ mesmo se observa para o caso em que a pressão média de evaporação, isto é, a ação do líquido em baixo fôr menor do que a pressão da atmosfera superior. O fenômeno continuará até chegar à condição de equilíbrio (dinâmico), que será atingido quando a probabilidade de evaporação igualar à de recondensação. De-fato, continuando a evaporação, irá sempre aumentando a concentração das

(*) É claro que, com pequenas modificaçöes, a teoria cinética pode ser aplicada também ao estado líquido, tendo em conta a continuidade entre o estado líquido e o gasoso. 
moléculas de vapor na atmosfera gasosa, sendo evidente que a probabilidade de recondensação dependerá dessa concentração.

Uma vez atingida a condição de saturação, a probabilidade de evaporação de uma molécula de líquido iguala a de condensação de uma de vapor; não é o fenômeno da evaporação que cessa, êle é simplesmente equilibrado por um fenômeno concomitante de condensação, de igual intensidade.

Agora, a probabilidade de evaporação pode, evidentemente, ser expressa pelo produto da área $\mathrm{S}$ da superfície de separação entre líquido e vapor por uma certa função não decrescente, $f(T)$, da temperatura absoluta $\mathrm{T}$ do fluido (*).

Quanto à probabilidade de condensação, é simplesmente proporcional à concentração molecular do vapor na atmosfera gasosa. Defato, se $n$ é o número total de moléculas de vapor contidas no recipiente, $\mathrm{S}$ a área da superfície de separação entre líquido e vapor, $\mathrm{V}$ o volume total, e a espessura da estratificação molecular (**), devido à lei de equirrepartição, o número $\mathrm{n}_{1}$ de moléculas de vapor presentes na superfície $S$ (tendo espessura e) será : $n_{1}=n e S / V$. Evidentemente, a probabilidade de condensação é ainda proporcional a êste número, quer dizer, em última análise, à área $S$ e à concentração molecular do vapor $\mathrm{n} / \mathrm{V}$. Todo o raciocínio acima é evidentemente aplicável também quando, além do vapor em exame, estiverem presentes outros gases ou vapores.

Resumindo, podemos dizer que se terá chegado à condição de saturação quando: Sf $(T)=K \operatorname{Sn} / V$, quer dizer, quando $f(T)=K n / V$.

A fórmula à qual chegamos exprime uma relação de interdependência unívoca entre a temperatura do fluido e a máxima concentração molecular do vapor, e é esta, a nosso ver, a lei que efetivamente regula o fenômeno da evaporação.

Notamos agora que a concentração molecular é um número proporcional d̀ pressão que o vapor teria se ocupasse, sdzinho, todo o volume do recipiente, com a mesma temperatura. A locução de Dalton é, porisso, para os fins práticos, e na maioria dos casos, equivalente à por nós adotada; esta é a razão pela qual dissemos que a lei de Dalton, pela forma geralmente expressa, fornece uma interpretação inexata de um fato físico real.

A demonstração por nós apresentada pode parecer pouco rigorosa, por deixar aparentemente de considerar o fato, já observado por Rankine(1),

(*) - Observamos que a forma da função $f(T)$ deve ser tal que adquira valor $\frac{1}{S}$ quando $\mathrm{T}$ igualar a temperatura crítica do fluido em exame ; para temperaturas superiores, a função manterá sempre valor igual a $\frac{1}{\mathrm{~S}}$, isto porque, multiplicando $\frac{1}{\mathrm{~S}}$ por $\mathrm{S}$ se obtém a probabilidade 1, quer dizer a certeza da evaporação.

(**) - Por simplicidade, supomos que as moléculas estejam estratificadas paralelamente à superfície de separação entre líquido e vapor ; é claro que tal suposição nada tira à generalidade das nossas considerações. 
de que a pressão da atmosfera superior tem influência sôbre o fenômeno da evaporação, que será tanto mais lento quanto maior fôr a pressão; além disso, a pressão não terá influência sôbre a quantidade total de líquido que poderá evaporar.

Ao contrário, achamos que as nossas considerações concordam plenamente com êste resultado experimental. De-fato, a igualdade por nós estabelecida entre as probabilidades de evaporação e de recondensação é válida, está claro, sòmente na condição de saturação, para a qual as expressões indicadas das duas probabilidades podem ser escritas. Antes de se chegar à condição de saturação, a probabilidade de recondensação pode ainda ser representada pela mesma expressão; - mesmo não se dando com a probabilidade de evaporação, na qual deveria ser acrescentado um têrmo dependente da pressão, exprimindo a maior ou menor resistência que uma molécula encontra para se vaporizar.

Assim é explicada a diferença essencial entre evaporação e ebulição; o primeiro é fenômeno puramente local, que também pode verificar-se sendo a pressão de evaporação (como valor médio) inferior à pressão da atmosfera gasosa ; o segundo, ao contrário, é fenômeno global, pois - fornecimento de energia calorífica (quer dizer, cinética) ao líquido é muito intenso: tôdas as moléculas da superfície de separação são empurradas para cima, com capacidade de se difundir ràpidamente na massa gasosa superior, deixando o espaço livre para a evaporação dos sucessivos estratos líquidos.

Ainda observamos que a explicação dada ao fenômeno da evaporação pode parecer um tanto sutil, devido à introdução do conceito de probabilidade de uma transformação; mas é justamente êste critério que regula, essencialmente, a maioria, se não a totalidade dos fenômenos físicos (9). Por exemplo, parece-nos que a tal critério se deve a explicação do fenômeno da difusão uniforme de dois gases, entre si.

Consideremos dois recipientes, contendo dois gases diferentes, com a mesma pressão, e a mesma temperatura (os volumes serão porisso proporcionais aos números de moléculas). Postos em comunicação, por exemplo, tirando uma parede divisória comum, depois de um tempo relativamente curto, constataremos uma distribuição pràticamente uniforme de cada um dos gases (e dos dois, no conjunto) em todo o recipiente.

Podemos supor a superfície de separação entre os recipientes como constituída de duas superfícies permeáveis distintas, infinitamente próximas. No comêço, numa das superfícies estarão contidas apenas moléculas de um dos gases, na outra sòmente as do outro. Isto significa que só se verifica a probabilidade de uma molécula atravessar a superfície no sentido do recipiente em que ela está inicialmente contida, para o outro. Assim vemos que a concentração molecular de um dos gases vai contìnuamente aumentando num dos recipientes e diminuindo no outro, acontecendo o inverso para o outro gás. Chegará um momento em que, para cada gás, a concentração molecular será a mesma nos 
dois recipientes; neste caso a probabilidade de uma molécula passar de um recipiente para o outro é equilibrada pela probabilidade de passagem no sentido contrário ; a mistura conservará, assim, composição homogênea, antes alcançada.

Nossa explicação para o fenômeno de difusão dos gases concorda, substancialmente, com a de E. Bloch (8), embora a forma da demonstração possa parecer diferente : de-fato, a demonstração de Bloch baseiase na variação da concentração molecular entre as sucessivas secções do recipiente em que o gás está contido. A diferença está no fato de que Bloch considera o fenômeno do ponto de vista dinâmico, ao passo que nós o consideramos como sucessão contínua de estados de equilíbrio, dinâmico, está claro. Achamos que a nossa explicação se apresenta em forma imediatamente intuitiva e demonstra claramente a razão da irreversibilidade do fenômeno da difusão; de-fato a difusão deve ser considerada não como um fenômeno reversível, que se manifesta não obstante a igualdade de pressões, mas, ao contrário, como um fenômeno intrinsecamente irreversível, causado pela desigualdade das concentrações. Nisto parece estar contida a confutação de um célebre paradoxo de Maxwell (*). Para chegarmos a êste resultado utilizamos o mesmo critério de probabilidade, ao qual Maxwell e Boltzmann foram levados, partindo do conceito da entropia, considerada como proporcional ao logaritmo da probabilidade de existência de um estado físico (8).

O mesmo fenômeno da difusão dos gases demonstra claramente a inexatidão da locução de Dalton; de-fato, se no exemplo precedente supusermos que os gases contidos nos dois recipientes sejam o mesmo, e ainda que os recipientes tenham volumes iguais, deveremos chegar à conclusão de que, depois da difusão, o gás esteja sujeito a uma pressão igual à metade da inicial, e continuando a raciocinar da mesma forma, deveríamos admitir que a pressão de um gás é uma grandeza absolutamente indeterminada e, porisso, indefinível. A nossa observação parece coincidir com aquela feita por Gibbs, tratando do aumento de entropia que se verifica depois da difusão de dois gases, observação esta citada por A. R. Ubbelohde (11), cujas considerações passamos a analisar. Sejam os valores iniciais da pressão $\mathrm{p}$ e da temperatura $\mathrm{T}$ iguais para os dois gases. Se $S_{1}$ e $S_{2}$ são as entropias dos dois gases, $n_{1}$ e $n_{2}$ os números de moléculas de cada um dêles, $\mathrm{C}_{1}$ e $\mathrm{C}_{2}$ os seus respectivos calores específicos moleculares sob pressão constante, $k_{1}$ e $k_{2}$ as correspondentes constantes da entropia, pode-se escrever (**):

$$
\mathrm{S}_{1}=\mathrm{n}_{1}\left(\mathrm{C}_{1} \log \mathrm{T}-\mathrm{R} \log \mathrm{p}+\mathrm{k}_{1}\right) ; \quad \mathrm{S}_{2}=\mathrm{n}_{2}\left(\mathrm{C}_{2} \log \mathrm{T}-\mathrm{R} \log \mathrm{p}+\mathrm{k}_{2}\right) \text {. }
$$

Depois da difusão, sendo $p_{1}$ e $p_{2}$ (pressões parciais dos dois gases) inferiores a $p$, ter-se-ia um aumento da entropia total, considerada como

(*) - Uns "demônios" que permitissem às moléculas de um gás passar so num sentido, e às do outro $s 6$ no outro sentido, operariam, sem despender trabalho, a separação dos dois gases.

(**) - É evidente, por homogeneidade de dimensões, que nessa fórmula, assim como na de Becquerel dada mais adiante, $R$ é expressa não em unidades mecânicas, mas em unidades calorificas. 
soma das entropias parciais, o que se apresenta como paradoxal, sobretudo no caso de serem os dois gases o mesmo gás.

Agora, parece-nos que a probabilidade de existência de cada um dos dois grupos de moléculas, considerado separadamente, não deve mudar por causa da difusão; conseqùentemente as suas entropias parciais deveriam permanecer invariadas. Êste resultado seria obtido, analìticamente, considerando que, depois da difusão, as duas pressões parciais sejam ainda iguais à pressão inicial comum. Com isto não queremos dizer que a entropia total do sistema não deva aumentar em consequêencia da difusão; ao contrário, isto deve acontecer, por ser o estado final mais provável do que o inicial. Este resultado pode ainda ser conseguido considerando as expressões antes indicadas das entropias parciais dos dois gases, nas quais entram as constantes $\mathrm{k}_{1}$ e $\mathrm{k}_{2}$ : de-fato, pensamos, não é necessário supor que a constante $\mathrm{k}$ do gás misturado seja igual à média. $\left(n_{1} k_{1}+n_{2} k_{2}\right) /\left(n_{1}+n_{2}\right)$ das constantes relativas dos dois gases componentes. Ao contrário, pode-se supor que $\mathrm{k}$ seja maior do que êste valor médio, e o aumento da constante exprimiria justamente a maior probabilidade que corresponde ao estado final.

Consideremos, de-fato, a expressão do aumento de entropia dada por J. Becquerel (4), que também trata do mesmo fenômeno, referente a uma mistura de vários gases. A expressão é a seguinte:

$$
\mathrm{S}=-\mathrm{R} \text { Znilog } \gamma \mathrm{i}
$$

onde $n_{i}$ é o número de moléculas do gás da ordem $i$, e $\gamma^{i}$ é a relação $\mathrm{n}_{\mathrm{i}} / \mathrm{n}$, sendo $\mathrm{n}$ o número total de moléculas contidas na mistura (ou, por outra, no sistema isolado que se está considerando).

Assim sendo, a expressão pode ser transformada da seguinte forma : $\mathrm{S}=-R \Sigma \mathrm{n}_{\mathrm{i}}\left(\log \mathrm{n}_{\mathrm{i}}-\log \mathrm{n}\right)=R\left(\log n \Sigma \mathrm{n}_{\mathrm{i}}-\Sigma \mathrm{n}_{\mathrm{i}} \log n \mathrm{i}\right)=R\left(n \log n-\Sigma n_{\mathrm{i}} \log n_{\mathrm{i}}\right)$.

Nesta forma fica evidente a razão do aumento de entropia. De-fato, basta supor que, na fórmula acima indicada para a entropia, a constante $\mathrm{k}$ seja igual a : $\alpha+\operatorname{logn}$, sendo $\alpha$ uma verdadeira constante. Assim, o têrmo nlogn (que depende só do número de moléculas) está a indicar que, independentemente dos valores da pressão e da temperatura, o arranjo mais provável das moléculas é o que corresponde à sua equirrepartição.

Passando agora ao caso de uma mistura de gases, a expressão $\Sigma n_{i} \log n_{i}$ exprimiria simplesmente a probabilidade de, em cada grupo de moléculas, se obter a equirrepartição; mas não exprime a probabilidade de equirrepartição entre os vários grupos de moléculas. É porisso que, ao se efetuar a soma das entropias parciais, a expressão $\Sigma n_{i} \log _{i}$ deve ser substituida pelo têrmo nlogn: observe-se que o resultado dêste critério de soma se conserva invariado também no caso de misturas entre vários componentes, dos quais alguns sejam por sua vez já misturas de vários gases.

Para justificar a introdução do têrmo nlogn, devemo-nos lembrar que, originàriamente empregada apenas como grandeza termodinâmica, a entropia é definida por um processo de integração, contendo porisso 
uma constante de integráção, que deve permanecer verdadeiramente constante enquanto ficarmos no campo de transformações puramente termodinâmicas. Uma vez, porém, que seja introduzido o conceito probabilístico da entropia, a lei segundo a qual a entropia de um sistema isolado tende continuamente a aumentar adquire uma significação muito mais ampla, devendo ser aplicada a qualquer caso de transformação espontânea, ainda que não seja de caráter termodinâmico: 0 que demonstra que, a-pesar do aspecto talvez um tanto artificial, a introdução que fizemos se justifica plenamente. De-resto, é interessante notar que já $\mathrm{H}$. Poincaré (*) observava que, a rigor, se deveria admitir que a entropia de uma mistura é igual à soma das entropias parciais dos componentes, mais uma função desconhecida das proporções dos vários gases na mistura; e a nossa interpretação leva justamente a definir qual possa ser tal função. Ademais, J. Becquerel, tratando do assunto (4) assim se exprime: "Deve-se frisar que esta variação de entropia é absolutamente independente da natureza dos gases que se misturam por difusão. Poder-se-ia então ser levado a aplicar o resultado para $\circ$ caso em que se põem em comunicação dois recipientes contendo - mesmo gás, à mesma temperatura e sob a mesma pressão; todavia se chegaria assim a um resultado absurdo, pois é evidente que não há mudança alguma. Estamos aquí em presença de um caso bem estranho de descontinuidade: a variação de entropia ou é nula ou igual a "certo valor" ; e a contradição parece não ter sido eliminada.

A nossa hipótese elimina o absurdo, mostrando que a observação de Gibbs nada contém de paradoxal, ou seja a entropia de uma molécula não é independente do número total de moléculas, mas é, ao contrário, estritamente ligada a êste, o que parece concordar perfeitamente com os resultados fundamentais da teoria cinética.

De-fato, repetimos, a entropia deve ser considerada como proporcional ao logarítmo da probabilidade de existência de um estado físico; assim sendo, a presença do têrmo logn, na expressão da entropia de uma molécula, indica uma probabilidade intrínseca de existência da própria molécula proporcional ao número n. Este resultado apresentase perfeitamente lógico, pois, quanto maior fôr o número total de moléculas, tanto maior será o número de posições que a molécula considerada terá probabilidade de ocupar, para cada grupo estatístico. E é justamente êste aumento de probabilidade intrínseca de existência, independentemente da pressão e da temperatura, que interpreta analiticamente a tendência dos gases de se difundirem um no outro e perderem a sua individualidade, o que, insistimos, constitue a essência da teoria cinética dos gases.

Ainda o mesmo critério de probabilidade, expresso analiticamente como concentração molecular dos componentes de uma mistura, explica, a nosso ver, os fenômenos osmóticos.

Neste último caso, sendo as paredes divisórias semipermeáveis, o equilíbrio de concentrações pode estabelecer-se sòmente para um dos

(*) - Citado por J. Becquerel (4). 
componentes da mistura (o diluente); assim é que as concentrações totais ficam diferentes, e da mesma forma, as pressões dos dois lados da parede divisória. Tôdas as experiências sôbre fenômenos osmóticos mostram simplesmente que nos dois ambientes há pressões totais diferentes, mas não que num mesmo ambiente os vários componentes estejam sujeitos a pressões diferentes. $O$ mesmo podemos dizer com relação às experiências que originalmente permitiram o enunciado da lei de Dalton (12).

Outro fenômeno análogo aos osmóticos, que pode ser explicado com os mesmos critérios, é o da passagem de um gás (hidrogênio) através de uma parede metálica (platina aquecida ao rubro), permeável só para aquêle gás, fenômeno êste que se produz também quando à pressão total interna do recipiente é inferior à pressão externa (4).

Queremos observar ainda outro ponto. Dissemos antes que $G$. Bruhat não aceita a nossa interpretação. Ao ler-se o que êle escreve, tem-se a impressão de que a aceitaria, por ser mais plausível (15). aparente absurdo de admitir vapor de água, a $0^{\circ} \mathrm{C}$, sob a pressão atmosférica, parece obrigá-lo a renunciar a primeira interpretação e a adotar, malgrado seu, a segunda.

A êste respeito, Bruhat justifica a sua interpretação, partindo também da nossa observação da equirrepartição das moléculas no recipiente e da perda de individualidade das mesmas; mas devemos confessar que não nos parece perfeitamente claro o seu raciocínio. $O$ autor se exprime assim: "Deve-se então admitir que os gases se misturem ainda mais intimamente, sem que alguma partícula, por pequena que seja, conserve a sua individualidade. Cada gás ocupa todo o volume da mistura, estando sujeito a uma pressão parcial igual à pressão que teria, se ocupasse sòzinho o volume V...".

Parece-nos que se deva interpretar mais ou menos assim: considerando, por exemplo, um elemento de superfície de $1 \mathrm{cmg}$., nêle estarão presentes moléculas de cada um dos gases, nas mesmas proporções em que se encontram na mistura completa. Assim sendo, a fôrça que se manifesta sôbre a superfície (pressão, por ser a superfície unitária) é igual à soma das fôrças correspondentes a cada grupo de moléculas, separadamente : isto é, a pressão total é igual à soma das pressões parciais. Repetimos: não nos parece claro que se deva interpretar assim; mas, se assim fôr, observamos que a pressão deve ser considerada como limite da relação entre a fôrça exercida e a superfície sôbre a qual ela se manifesta. Portanto, no caso citado, a percentagem $\mathrm{x}$ de moléculas de qualquer um dos gases, presentes na superfície unitária considerada, age também sôbre uma percentagem $\mathrm{x}$ da própria superfície; isto é, a fôrça sôbre a unidade de superfície, como valor limite, fica a mesma para todos os gases, e é essa que se deve entender como pressão parcial, que fica sendo, para cada gás, igual à pressão total. 
Talvez a verdadeira razão da contradição que apontamos resulte mais clara, analisando as considerações de J. Jeans (17), sôbre o assunto. Êste autor determina a seguinte expressão da pressão:

$$
\text { pressão }=\frac{2 \times \text { energia cinética }}{3 \times \text { volume }}
$$

"energia cinética" é a energia cinética total correspondente ao movimento de tôdas as moléculas do gás: "volume" é o volume total do gás. Assim, "a pressão é igual aos dois terços da energia cinética por unidade de volume", e sôbre esta definição não há dúvida alguma.

Sucessivamente, porém, perde-se o rigor lógico: de-fato, Jeans procede assim: "Visto que as energias cinéticas são aditivas, as pressões devem também ser aditivas. Assim, a pressão exercida por uma mistura de gases é a soma das pressões exercidas pelos constituintes da mistura, separadamente. Esta é a lei de Dalton."

Não nos parece que seja assim. Na expressão acima, referente à pressão, vimos que entra a "energia cinética por unidade de volume" ; mas é claro que a "unidade de volume" não deve ser considerada como a unidade de volume convencional, dependente do sistema métrico adotado, mas deve ser interpretada como a unidade de volume, verdadeira entidade física, que é o volume total dividido pelo número de moléculas ou, por outra, o volume de um cubo, tendo por centro uma molécula, e cujo lado é igual à distância média intermolecular ${ }^{*}$ ). De-fato, a pressão é sempre definida através de um processo de derivação, de forma que deve ser considerada como limite da relação (à parte o fator 2/3) entre energia cinética e volume. Agora, sendo a molécula uma entidade física indivisível, o limite da energia cinética é a energia cinética de uma molécula $e$, por conseguinte, o volume é o que corresponde a uma molécula. Em outras palavras, se n é o número total de moléculas contidas no volume $\mathrm{V}$, podemos escrever assim:

$$
\begin{aligned}
\text { pressão }= & \frac{2 \mathrm{n} \times \text { energia cinética de uma molécula }}{3 \mathrm{n} \times \text { vol. correspondente a uma molécula }}= \\
& \frac{2 \text { energia cin. de uma mol. }}{3 \text { vol. corr. a uma mol. }}
\end{aligned}
$$

$\mathrm{Na}$ expressão atrás, a rigor, a energia cinética de uma molécula representa a média das energias cinéticas das várias moléculas; mas é bom não esquecer que, na teoria cinética, a pressão é determinada aplicando o teorema da variação da quantidade de movimento; no que está implícita uma integração, seguida de uma divisão, por um certo tempo $\mathrm{dt} ;$ isto é, a energia cinética de uma molécula é já uma energia cinética média no tempo, para aquela molécula; e como, devido à equirrepartição, as energias cinéticas médias no tempo são iguais para tôdas as moléculas, resulta que a "energia cinética de uma molécula" representa não só a média entre as energias cinéticas das várias moléculas, mas também a energia cinética média no tempo para

(*) - É êste o volume ao qual pretendíamos referir-nos ao falar, mais acima, da "esfera de ação de uma molécula". 
uma molécula. Assim, omitindo por brevidade o atributo "no tempo", resulta :

$$
\text { pressão }=\frac{2 \text { energia cinética média de uma molécula }}{3 \text { volume correspondente a uma molécula }}
$$

e nesta forma parece absolutamente claro porque é que pressão parcial e pressão total são a mesma cousa.

Ainda há mais. Na nossa opinião há uma ambiguidade sôbre a significação do têrmo pressão. De um lado, a pressão é considerada como ação das moléculas gasosas sôbre as paredes do recipiente; $e$ a expressão cinética da pressão é obtida considerando o efeito médio dos choques, contra um elemento de parede, das moléculas gasosas que vão golpeá-lo sucessivamente; neste sentido não há inconveniente em se dizer que a pressão total é a soma das pressões parciais, com a condição de não esquecer a significação simbólica desta expressão que, de modo mais completo, deveria ser assim expressa: "a pressão sôbre as paredes do recipiente é igual à soma das pressões que cada gás exerceria caso ocupasse sòzinho, com a mesma temperatura, o volume total do recipiente."

Sucessivamente, porém, aplicando o princípio de ação e reação (ou melhor, de interação) a pressão adquire um perfeito significado também como estado de tensão do meto; assim, estatisticamente, cada elemento de superfície deve exercer uma ação igual e contrária àquela a que está submetido sôbre o estrato gasoso imediatamente adjacente, o qual deve transmití-la ao sucessivo, e assim por diante. Assim chegamos a definir, em cada ponto da massa gasosa, e independentemente da presença de uma molécula gasosa naquele ponto, o valor da pressão (numèricamente igual àquela suportada pelas paredes) como limite da relação, no espaço e no tempo, entre as energias cinéticas totais das moléculas que vieram ocupar um certo elemento de volume e o volume do elemento. Isto é, a pressão não pode ser considerada como simples efeito de parede, mas deve conservar a sua significação no seio da massa gasosa, caso êste em que a "pressão parcial" não tem maior significação, nem mesmo simbólica.

Antes de concluir, procuraremos analisar as opiniões de diferentes autores com relação ao problema que nos interessa.

A interpretação de Dalton é aceita sem ambiguidade por Rankine (1), J. Becquerel (4), V. W. e G. A. Young (7), G. Chaussin e G. Hilly (12), L. Lecornu (3), C. F. Taylor e E. S. Taylor (14).

A. R. Ubbelohde, embora não faça menção explícita da lei de Dalton, também aceita evidentemente a mesma explicação, conforme observamos antes, quando trata da entropia de uma mistura.

E. Bloch, por um lado, parece aceitar a nossa interpretação, quando diz que a pressão de uma mistura é igual à soma das pressões que os diferentes gases teriam, se ocupassem sòzinhos o volume da mistura, sendo êste o enunciado que êle dá à lei de Dalton (8). Por outro lado, porém, o mesmo autor parece aceitar a interpretação de Dalton, pois atribue uma existência física real à pressão osmótica (8). 
P. Dumanois (5) apresenta simplesmente a expressão analítica da lei de Dalton, escrevendo que a pressão da mistura é igual à soma das pressões parciais, sem indicar se estas últimas devem ser consideradas como pressões efetivas a que estão sujeitos os gases. Na mesma fórmula, porém, êle escreve ainda a pressão total da mistura em função das concentrações dos vários componentes, forma esta que evidencia gue a pressão total depende sòmente do número total de moléculas presentes na unidade de volume, e que as pressões parciais intervêm sòmente quando se divide o número total de moléculas pelos números parciais que correspondem aos diferentes grupos moleculares.

J. Chappuis e M. Lamotte (2) dão inicialmente o enunciado de Dalton, observando, porém, logo em seguida, que o resultado das experiências de Dalton é melhor expresso pelo enunciado de Leduc e Amagat, que é o nosso, e assim se exprime: "O volume ocupado por uma mistura de gases é igual à soma dos volumes que ocupariam os componentes sob a pressão e à temperatura da mistura; isto é, cada um dos gases deve ser considerado como sujeito à pressão total." A mesma interpretação parece que os dois autores dão mais adiante, tratando do fenômeno da evaporação, embora ela não esteja explìcitamente expressa (2). Posteriormente, porém, calculando o pêso de uma mistura de gases e vapores, êles se baseiam nas tensões parciais, considerando-as entidades físicas reais (2).

A interpretação de Inchley (13) também não é perfeitamente clara. Parece, porém, que não atribue existência real d̀ tensões parciais, pois o seu enunciado da lei de Dalton é o seguinte: "A pressão exercida sôbre as paredes dum recipiente por uma mistura de gases que não reagem é igual à soma das pressões que seriam exercidas pelos gases, se êles estivessem presentes separadamente".

H. C. Weber (16) apresenta os dois enunciados da lei, o de Dalton e o de Amagat. Êste autor observa oportunamente que os dois enunciados, equivalentes no caso de gases perfeitos, não mais o são no caso de gases reais ; e que nos cálculos usuais para análise de gás é implícito aceitar a interpretação de Amagat.

M. Boll e A. Féry (6) seguem evidentemente a interpretação de Dalton. Estes dois autores, a propósito da dissolução de gases na água, exprimem o fenômeno em função das concentrações moleculares (6); mas é claro que tais concentrações são consideradas não como causa determinante do fenômeno, mas como efeito das pressões parciais.

E. Fermi (10) se exprime assim: "Uma mistura de vários gases é governada por leis muito semelhantes àquelas a que obedece um gás quìmicamente homogêneo. Chamaremos pressão parcial de um componente duma mistura de gases a pressão que tal componente exerceria se, sòzinho, enchesse o volume ocupado pela mistura, à mesma temperatura da mistura. Podemos formular agora a lei de Dalton para misturas de gases da seguinte forma:

A pressão exercida por uma mistura de gases é igual à soma das pressões parciais de todos os componentes presentes na mistura ..." 
Parece que nas premissas esteja bem definida a significação simbólica da expressão pressão parcial ; por outro lado, o enunciado da lei dá lugar a ambiguidade de interpretação.

Já falamos da interpretação de J. Jeans, mas queremos observar que, em outra ocasião (17), êle dá um enunciado diferente da lei, assim :" . . a pressão exercida por uma mistura de gases diferentes é igual à soma das pressões que seriam exercidas pelos constituintes separadamente, - que nos leva novamente à lei de Dalton."

Como se depreende das citações feitas, à-parte poucas exceções, nem sempre bem definidas, a interpretação mais difundida é a que corresponde ao enunciado de Dalton; é é evidente que assim deva ser, conquanto se considerem os fenômenos físicos como determinados essencialmente pelas pressões dos elementos sujeitos a transformação. Procuramos demonstrar que os mesmos fenômenos físicos podem ser igualmente bem interpretados, atribuindo valor determinante às concentrações moleculares, e, pensamos, com a vantagem de se poderem assim eliminar incongruências inevitáveis, quando se aceite a primeira interpretação.

Resumindo, todos os fenômenos de transformação (evaporação, difusão de gases, pressão osmótica), nos parecem ser regulados não pelas pressões parciais dos elementos sujeitos a transformação, mas, pura e simplesmente, pelas concentrações moleculares, as quais, por outro lado, são, em cada caso, proporcionais às assim chamadas pressões parciais, que carecem, a nosso ver, de existência física real.

\section{LITERATURA CITADA}

1. Ranhine, W. J. Macquorn. Manuel de la Machine a Vapeur (traduit de l'anglais par G. Richard). Dunod Ed., 1878.

2. Chappuis, J. e M. La motte. Leçons de Physique Générale, Tome I. GauthierVillars et Cie., Ed., 1907.

3. Lecornu, L. Cours de Mécanique. Tome III. Gauthier-Villars et Cie., Ed., 1918.

4. Becquerel, J. Cours de Physique-Thermodynamique. Ed. Librairie Scientifique J. Hermann, 1924.

5. Dumanois, P. Moteurs a Combustion Interne. Librairie J. B. Bailliere et Fils, 1924.

6. Boll, M. e A. Féry. Précis de Physique. Tome II. Dunod Ed., 1927.

7. Young, V. W. e G. A. Young. Elementary Engineering Thermodynamics. McGrawHill Book Co., 1936.

8. Bloch, E. Théorie Cinétique des Gaz. Librairie Armand Colin Ed., 1937.

9. Broglie, L. de. Matière et Lumière. Albin Michel Ed., 1937.

10. Formi, E. Thermodynamics. Prentice-Hall, Inc., 1937.

11. Ubbelohde, A. R. An Introduction to Modern Thermodynamical Principles. Oxford at the Clarendon Press, 1937.

12. Chaussin, C. e G. Hilly. Chaleur et Thermodynamique. Dunod Ed., 1938.

13. Inchley's. Theory of Heat Engines. (Edited and revised by H. Wright Baker). Longmans, Green and Co., 1938.

14. Taylor, C. F. $\theta$ E. S. Taylor. The Internal Combustion Engine. International Textbook Company, 1938.

15. Bruhat, G. Cours de Physique Genérale-Thermodynamique. Masson et Cie., Ed., 1939.

16. Weber, H. C. Thermodynamics for Chemical Engineers. John Wiley and Sons, Inc., 1939.

17. Jeans, J. An Introduction to the Kinetic Theory of Gases. Cambridge at the University Press, 1940.

1.8. Foá, A. Misturador automático para motores a gás-Bragantia 3:151-154, fig. 1-1943. 